\title{
CLINICAL CASE OF YATROGENIC HYPERCORTISOLISM IN PREGNANT WOMAN WITH ADRENAL INSUFFICIENCY
}

\author{
Volkova N.I., Porksheyan M.I., Kanaeva S.A., Davidenko I.U. \\ Rostov State Medical University, Rostov-on-Don \\ Rostov-on-Don, Russian Federation, dim3.rostgmu@gmail.com
}

\section{Background}

Adrenal insufficiency (Al) in pregnant women is difficult to manage because of similarity between clinics of decompensation of $\mathrm{Al}$ and gestational toxicosis. Objective difficulty is absence of clinical guidelines of management of pregnant patients with Al.

\section{Clinical case}

Pregnant woman, 29y.o. 22 week of gestation. Her complaints were high blood pressure, face edema, hyperglycemia, weight gain. She asked second opinion about established diagnosis and treatment.

\section{Patient anamnesis}

\begin{tabular}{|c|c|}
\hline \multicolumn{2}{|c|}{ Before pregnancy } \\
\hline Diagnosis of Al was established & Al with treatment by supraphysiological doses of \\
\hline Daily dose: 50 mg hydrocortisone & hydrocortisone \\
\hline
\end{tabular}

\section{$6^{\text {th }}$ week of pregnancy}

She began to complain of fatigue and dizziness

Complaints developed after increased doses

Daily dose increased: $100 \mathrm{mg}$ hydrocortisone

\section{$15^{\text {th }}$ week pregnancy}

Preeclampsia and gestational diabetes were suspected

In the first trimester preeclampsia is not possible to Antihypertensive drugs and insulin were prescribed

\section{happen.}

\section{During our consultation}

1. Diagnosis of iatrogenic hypercortisolism was established

2. The dose of hydrocortisone was gradually decreased to $25 \mathrm{mg}$ per day

3. Insulin, hypotensive drugs were stopped.

\section{Results}

Her condition became better in a few days. In one month complaints disappeared.

\section{Conclusions}

1. In the first trimester treatment of Al may be difficult because symptoms of $\mathrm{Al}$ are seen in pregnancy. It is easy to assign insufficient doses.
2. Clinics of iatrogenic hypercortisolism is similar to preeclampsia, the risk of overdose is high.

3. Because of absence of clinical guidelines, doctors must strictly follow to existing recommendations in order to avoid such mistakes. 